\title{
Legal Cannabis Market Shares during Canada's First Year of Recreational Legalisation
}

\author{
Michael J. Armstrong \\ Associate professor \\ michael.armstrong@brocku.ca \\ Goodman School of Business, Brock University \\ 1812 Sir Isaak Brock Way \\ St Catharines, Ontario, L2S 3A1, Canada
}

\begin{abstract}
Background: This study estimated legal products' share of Canada's total cannabis consumption during the first year of recreational legalisation, October 2018 to September 2019.

Methods: Government data was used to estimate monthly recreational sales in dollars per capita, grams per user, and percentage share of kilograms or litres consumed. As explanatory factors, the analysis considered provincial differences in retail pricing (percentage mark-ups) and store density (stores per million users), as well as national monthly production of dry cannabis (kilograms) and cannabis oil (litres) finished products.
\end{abstract}

Results: Legal recreational products' share of Canada's overall cannabis consumption began at $7.8 \%$ in October 2018 and grew to $23.7 \%$ by September 2019, with an average of $14.5 \%$ over the first 12 months. Sales growth was delayed by shortages of both dry cannabis products and licensed stores, but not cannabis oils. Across the 10 provinces, legal recreational shares in September 2019 varied from 13\% to 70\%; differences in store densities and retail prices partly explained the variation. Prince Edward Island's large 70\% share seemed due to it having minimal product shortages, high store densities, and low prices.

Conclusions: Legal recreational products captured market share to the extent they were available, accessible, and low-priced. Problems with those factors slowed the initial expansion of legal product sales but also suggested ways to gradually increase their market share.

Keywords: cannabis, legalisation, pricing, accessibility

(C) 2020. This manuscript version is made available under the CC-BY-NC-ND 4.0 license http://creativecommons.org/licenses/by-nc-nd/4.0/. It is the author's accepted manuscript for:

Michael J. Armstrong, "Legal cannabis market shares during Canada's first year of recreational legalisation”, International Journal of Drug Policy, Volume 88, February 2021, 103028, https://doi.org/10.1016/j.drugpo.2020.103028. 


\section{Introduction}

On October 17, 2018, Canada legalised cannabis for recreational use. There were many debates before that day about legalisation's potential impacts on public health, social justice, and other issues (Canadian Centre on Substance Use and Addiction, 2019; Armstrong \& Malleck, 2019). After legalisation, those debates were joined by new ones concerning actual outcomes.

This study focused on one such outcome: the share of Canada's total cannabis consumption represented by legal products. It estimated those market shares during the first year of recreational legalisation, October 2018 to September 2019, for the country overall and for its 10 provinces. It also calculated dollars per capita and grams per user as secondary measures of sales. As possible explanatory factors, the study considered provincial differences in retail pricing and store density, as well as production of dry cannabis and cannabis oil finished goods.

This topic is worth studying for several reasons. First, it is interesting from business and economics perspectives because newly created legal firms had to compete against established illegal incumbents. How successfully did the newcomers penetrate the existing market?

Second, it is interesting from the perspectives of fields like health care, law enforcement, and social justice because users' adoption of legal products influences legalisation's impacts in those fields. For example, the extent to which legalised sales might reduce physical harms to users (Hammond, in press) and/or law enforcement harms to minorities (Hart, 2020) partly depends on how many users adopt legal products. To what extent did Canadians do so?

Third, the topic is interesting from an interdisciplinary drug policy perspective because it involved government regulations interacting with business practices in ways that could support or undermine policy objectives. For example, decisions regarding how much to produce, what prices to charge, or how many stores to open are routine in most industries but draw government intervention with cannabis. How influential were those factors on Canada's outcomes?

\section{Legalisation elsewhere}

Uruguay was the first country to legalise recreational cannabis, beginning in 2014 via a heavily regulated approach. Users could grow their own plants, join a cannabis club, or register to buy from a pharmacy, but could not combine those methods. Only two producers and a few pharmacies participated; they offered just five cannabis varieties with modest THC levels and government-set prices. Consequently, relatively few users registered (Obradovic, in press).

In the U.S., 11 states so far have authorised recreational sales, generally with more private-sector involvement than Uruguay had allowed. For example, both Washington and Colorado opened their first recreational stores in 2014. Washington was relatively cautious: it limited the number of stores, required retailers to be independent of producers, and prohibited users from growing their own plants. By contrast, Colorado allowed home growing and did not limit store numbers (Hunt \& Pacula, 2017; Obradovic, in press). However, cannabis remained illegal under U.S. federal law even in those states, and the federal government enforces that law wherever it has sole jurisdiction. E.g., state-licensed cannabis firms cannot deduct expenses from 
their federal income taxes, and military veterans caught using cannabis risk losing their benefits (Owermohle, 2019). Consequently, the outcomes of U.S. "state-level legalisation" might not represent what countries could expect from nationwide approaches.

\section{Canada's approach}

Canada's official legalisation goals included protecting public health by letting users access quality-controlled products; and protecting public safety by reducing criminal activity (Cannabis Act, 2018, Section 7). Legalisation obviously could also provide economic benefits such as company profits, employee wages, and government tax revenues. All these outcomes depended on users buying legal products.

The federal government regulated all cannabis producers and products nationwide; it also oversaw medical cannabis sales, which were done online directly from producers to patients. Because recreational producers had to meet the same quasi-pharmaceutical standards that applied to medical ones, it was almost impossible for existing illicit producers to obtain licenses; most presumably continued operating illegally. During year one of legalised sales, dry cannabis flower and ingestible cannabis oil were the main products allowed, though seeds and plants were also sold. Cannabis concentrates, edibles, lotions, and vape oils remained illegal until year two.

Meanwhile, the country's 10 provincial governments regulated recreational cannabis retailing and consumption within their own jurisdictions. Every province allowed online and storefront sales in some manner: some provinces created government-owned retailers, some issued licenses to businesses, and some did both. Each also set a minimum consumption age, either 18 (in Alberta and Quebec) or 19 (elsewhere). This variety of provincial approaches created a natural experiment regarding the impact of regulatory differences on legalisation outcomes (Hunt \& Pacula, 2017; Lancionea, et al., 2020).

One variable in that experiment was pricing, a business decision that has interested many cannabis researchers (Childs \& Stevens, 2019; Davenport, in press; Hollenbeck \& Uetake, 2020; Hunt \& Pacula, 2017; Smart et al., 2017). Setting prices and taxes lower could draw more users away from illegal sources; but setting them higher could discourage overuse and increase government revenues. Many provinces initially envisioned retail prices starting around $\$ 10$ per gram (\$ Canadian), but Quebec's averaged under \$8 (Société québécoise du cannabis, 2019).

Another variable was the size of provincial retail networks relative to their markets. Where retailers were privately owned, some provinces limited license numbers via lotteries or calls for proposals, while others set no maximums. Where retailing was publicly owned, some provinces began with very few outlets, while others created widespread networks.

\section{Operational challenges}

While legal sales began enthusiastically, problems quickly arose. Many consumers and retailers complained about product shortages; one wholesaler received only $30 \%$ of what it had ordered during the first six months (Manitoba Liquor \& Lotteries, 2019: 14). Some producers struggled with mould, insects, or packaging problems (Doucette, 2020). Two provinces 
temporarily halted retail licensing because of the shortages (French, 2018; Ontario Ministry of Finance, 2018). However, federal politicians repeatedly denied widespread shortages existed, and blamed provincial distributors for any shortfalls (Blair, 2019a, 2019b; Levasseur, 2019).

\section{Research questions}

By estimating and analysing legal products' share of consumption, this study addressed several public policy questions regarding Canada's cannabis legalisation experience.

1. How successful were the new legal products at competing against existing illegal ones?

2. Were legal sales hindered by shortages of products from federally regulated production, or by shortages of stores within provincially regulated retailing?

3. Which of the 10 provinces' regulatory approaches best supported sales during the first year?

\section{Method}

\section{Overview}

This study analysed publicly available data from two federal government departments, Health Canada and Statistics Canada, as well as from provincial cannabis agencies. Because the data came from several sources, in differing units, and in differing degrees of aggregation, several steps were required to make them comparable.

- An existing national consumption estimate was broken down into provincial estimates proportionate to their user populations.

- Sales, production, and inventory levels were used to estimate producer inventory losses.

- Pricing information and retail store counts were tabulated from provincial web sites.

- Provincial retail sales in dollar terms from several sources were combined and then adjusted for provincial pricing.

- Provincial sales in dollar terms were compared to national sales in product volume terms to estimate provincial sales in product volume terms.

- Sales volumes were compared to consumption volumes to estimate market shares.

- Market shares were compared to production volumes, pricing levels, and store densities to look for explanatory relationships.

\section{Measurement units}

One way to measure cannabis sales is in dollars per capita: i.e., total sales dollars divided by total population. This ratio is easily calculated but has weaknesses for policy analysis. Using dollars in the numerator neglects price differences between licit and illicit sources, between medical and recreational distributors, and between jurisdictions. Similarly, using total population in the denominator neglects provincial differences in usage. Per capita sales dollars therefore imply different things in different contexts, making them less comparable.

Sales can also be measured in grams per user. This ratio is more useful because it considers cannabis amounts rather than their costs, and because it focuses on users rather than 
entire populations. However, when counts of grams and users must be estimated, there are more opportunities for errors to occur.

A third way to measure cannabis sales is via product volume market shares: i.e., kilograms sold as a percentage of kilograms consumed. This is the most interesting measure but also requires the most approximations and assumptions.

This study primarily considered market shares, especially when analysing Canada's overall outcomes. It used dollars per capita and grams per user as secondary measurements, especially when comparing provincial outcomes; this ensured the latter comparisons were not overly affected by the approximations needed to prepare the provincial data.

\section{Consumption}

In preparation for legalisation, Health Canada commissioned the Marijuana Policy Group (MPG, 2018) to estimate total cannabis consumption (illegal, legal medical, and legal recreational combined) for the first year of recreational sales. MPG's calculations accounted for differing prevalence and intensity of use across four groups of provinces (Atlantic, Quebec, Ontario, and Western) and four frequency-of-use categories (less than monthly, monthly, weekly, and daily-or-near-daily), using data from Health Canada's (2017) Canadian Cannabis Survey. MPG estimated Canada's annual adult (age 18+) consumption at 926 tonnes of dry cannabis or its equivalent, within a $95 \%$ prediction interval from 752 to 1,138 tonnes.

MPG (2018) was not the only available cannabis demand estimate (see MPG (2018) or Sen and Wyonch (2018) for surveys of other estimates), but it offered several advantages. First, it was commissioned by the department that collected national sales and production data; that commonality provided more face validity for this study's comparisons. Second, it estimated consumption in kilograms, whereas some industry analysts prepared forecasts in dollars. Third, it was relatively recent, having been released in September 2018; by contrast, e.g., the Office of the Parliamentary Budget Officer (2016) estimate of 655 tonnes (within a range from 378 to 1,017 tonnes) was two years older. And fourth, its calculations used Canadian user data; whereas, e.g., the Sen and Wyonch (2018) recreational-only estimate of 600 tonnes (within a range from 384 to 800 tonnes) was based on American consumption per capita. All the estimates had wide prediction intervals due to the challenges of estimating illicit demand (Anderson, 2020).

For its part, Statistics Canada (2019a) conducted a National Cannabis Survey (NCS) each quarter during 2018 and 2019 to estimate prevalence. Rotermann (2020) summarized the results by comparing the three surveys before legalisation to the four that followed it; she omitted the 4th-quarter 2018 survey because it overlapped legalisation day. Three of the surveys also asked users about their preferred consumption method: on average, $68 \%$ preferred smoking, while $32 \%$ chose vaping, eating, or another method.

MPG (2018) did not estimate consumption for individual provinces. To derive those, this study subdivided each regional estimate in proportion to each province's share of all users within that region, based on the 2019 NCS user counts. Similarly, the 2019 NCS consumption method preferences were used to divide MPG's 926 tonne total into two broad product categories: dry 
cannabis (including pre-rolls, etc.) at 628 tonnes; and processed products (including oils, edibles, etc.) at 298 tonnes. Because most processed product formats were not yet legal, most of the latter category was inaccessible to legal sellers.

Comparison of MGP's regional estimates to the 2019 NCS user counts implied that MPG had used consumption-per-user rates about 31\% below the national average for Quebec, $13 \%$ above average for the four western provinces, and $1 \%$ above average for the other five, presumably reflecting regional usage differences. MPG also excluded consumption by youths aged 17 or under. The NCS surveyed users aged 15 to 17, but the data quality was low: Rotermann (2020) flagged that age group's total user count as "use with caution" and the key daily-or-almost-daily user count as "too unreliable to be published". Neither the NCS nor the Canadian Cannabis Survey estimated usage by youths aged 14 or under.

\section{National production and sales}

The Canadian government required licensed producers and provincial distributors to submit monthly operating reports. Health Canada (2020) summarized that data by posting national totals, measured in kilograms of dry and litres of oil, for the following finished goods quantities: production, producer month-end inventories, distributor month-end inventories, recreational sales, and medical sales. By comparing the inventory changes to the sales and production numbers, it was possible to calculate the amounts shipped to distributors and the amounts lost (scrapped, etc.) by producers. Health Canada also posted monthly exports, but only for the first six months. Since those represented less than $1 \%$ of domestic sales, this study used the 6-month average in place of the missing values.

Figure 1 displays the monthly legal sales volumes for the 12 months before recreational legalisation and the 12 months afterward. From October 2017 to September 2018, when only medical use was legal, sales totalled $25,694 \mathrm{~kg}$ of dry cannabis and 45,020 litres of cannabis oil. During the next 12 months, oil sales doubled to 103,819 litres (57,763 medical plus 46,056 recreational) and dry sales quadrupled to $108,814 \mathrm{~kg}$ (20,153 medical plus 88,661 recreational).

\section{Provincial retailing}

Both in-store and online sales occurred in all provinces, but the latter were less important. The percentage of legal recreational sales occurring online was 43.4\% in October 2018, but quickly fell as more stores opened, hitting 5.9\% in September 2019 (Statistics Canada, 2019b). Provinces with wide store coverage saw minimal online sales: e.g., just $1.5 \%$ for Prince Edward Island (Prince Edward Island Cannabis Management Corporation, 2019: 28).

This study obtained counts of licensed retail stores from each provincial regulator's web site near the start of each month. Each province's store count was then divided by its 2019 NCS user count to calculate stores per million users as a measure of store density. Canada's total store count quintupled from 102 in October to 505 in September, pushing the store density from 19.8 to 98.3 stores per million users. Table 1 shows each province's store density for September 2019 as well as its 12-month average. 
Average retail prices were not so readily available, as most provincial governments were secretive about their pricing policies. Some studies have gathered pricing data, but mostly to compare licit prices to illicit ones. For example, Statistics Canada (2019c) crowdsourced data from users about the prices they had paid; but the samples were self-selected, small, and covered only dry cannabis. Mahamad et al. (2020) collected data in fall 2018 from retailer web sites about the prices they offered. However, it covered only dry cannabis and did not estimate salesweighted averages. Both studies reported illegal products being much cheaper than legal ones, though Mahamed's price gap was smaller than Statistics Canada's.

To overcome these data limitations, this study took an indirect approach. It assumed the mean prices provincial distributors paid to producers were roughly equal across the country, and then compared three factors that could create interprovincial differences in retail prices. (The study made no assumption about where provincial agencies bought their products.)

The first pricing factor considered was the combined provincial-federal sales tax, which ranged from $5 \%$ to $15 \%$. The second was the extra excise tax levied in three provinces; it ranged from $3.9 \%$ to $16.8 \%$. (The basic federal-provincial excise tax was ignored, as it was common to all provinces. That tax was charged as the greater of $\$ 1$ per gram or $10 \%$ of the producer's price; the $\$ 1$ flat rate applied in most cases.) The third was the average retail-plus-wholesale price mark-up, relative to producer prices. For six provinces, this mark-up was calculated from the provincial cannabis agency's year-end financial statements. For three provinces with only private stores (Alberta, Saskatchewan, and Manitoba), the wholesale mark-up (if any) came from the agency web site; to estimate a retail mark-up, the average of three major retailers' financial statements (Fire \& Flower, National Access Cannabis, and Hightide) was calculated. Nova Scotia disclosed too little information for its mark-up to be estimated; so, the mean of the other provincial rates was used. The resulting mark-up estimates ranged from $23 \%$ to $83 \%$.

Table 1 shows the three pricing factors for each province. The mark-up and added excise tax were used to translate retail sales to producer-priced sales; see next subsection. Combining those with the sales tax yielded a pricing multiplier to represent differences in what consumers paid in each province. For example, Ontario's cannabis agency charged retail prices $80 \%$ above what it paid producers, faced a 3.9\% extra excise tax on what it bought, and collected a $13 \%$ sales tax on what it sold. This implies Ontario's retail prices averaged $(1.80 \times 1.039)=1.87$ times its producer prices before sales tax, or $(1.87 \times 1.13)=2.11$ times after sales tax.

\section{Provincial recreational sales}

Provincial governments were also secretive about their sales. Each province reported its monthly recreational sale volumes to Health Canada within 15 days, but none published them. For this study, each province's agency was asked for its monthly dry and oil volumes for the first 12 months of sales; only Nova Scotia and Saskatchewan provided them.

To estimate the other provinces' sales volumes, the starting point was Statistics Canada's (2020) monthly retail sales survey, which reported recreational sales in dollars for each province. Its figures were estimates from samples of stores, rather than actual totals. Comparisons of those estimates to actual sales for 17 cases where quarterly or semi-annual totals were published 
showed the actuals averaged $4.8 \%$ above the estimates. So, this study used provincial agencies' reported sales where they were available, and otherwise used Statistics Canada's estimates after increasing them by $4.8 \%$. This combination valued Canada's first year recreational sales at $\$ 967$ million, rather than the $\$ 928$ million Statistics Canada had reported.

The next step was to estimate provincial sales volumes by comparing provincial sales dollars to Health Canada's national sales volumes. New Brunswick was handled first because of its detailed semi-annual reports. For the first half-year, it reported total sales for oil and dry separately, in both dollars and product volumes, allowing average dry and oil prices to be calculated. For the second half-year, the agency reported only in dollars. So, for months 1 to 6 , the adjusted Statistics Canada monthly dollar values were used to allocate New Brunswick's semi-annual kilogram and litre totals to the corresponding months on a prorated basis. For months 7 to 12, the semi-annual dry and oil sales dollar totals were divided by the dry and oil average prices, respectively, to yield approximate kilogram and litre totals. Those dry and oil volumes were then allocated to each month in proportion to its total dollar sales.

The volumes for New Brunswick, Saskatchewan, and Nova Scotia were subtracted from the Health Canada national totals, leaving the remaining quantities to be allocated across the other seven provinces. For that, each province's retail dollar sales total was first adjusted for mark-up and excise differences, effectively converting sales from retail prices to producer prices. (E.g., Ontario's October $\$ 12.3$ million of retail sales was divided by 1.87 to estimate producer sales at $\$ 6.59$ million.) Then each month's product volumes were allocated to individual provinces in proportion to their share of the 7-province producer price sales total. (E.g., Ontario's $\$ 6.59$ million represented $28.5 \%$ of October's producer-price sales, so that percentage of October's dry kilograms and oil litres was allocated to it.)

These steps yielded approximate recreational oil and dry quantities sold in each province and month. These were compared to the 2019 NCS user counts to calculate grams per user, and to the MPG (2018) consumption volumes to calculate market shares.

\section{Statistical models and software}

As part of the country-level data analysis, this study used AMOS 25 software to test a structural equation model (SEM) via an analysis of covariance approach. The SEM tested whether monthly production of dry and oil products influenced monthly store density; and whether those three variables influenced legal recreational products' monthly market share. The calculations used $N=12$ months of national measurements.

As part of the province-level data analysis, the study used Stata 15.0 and SPSS 25 software to perform panel data linear regression analysis. The analysis tested whether provincial mean retail price $(N=10)$, provincial monthly store density $(N=120)$, national monthly dry cannabis production $(N=12)$, and national monthly cannabis oil production $(N=12)$ influenced monthly provincial recreational sales. Stata was first used to perform Hausman tests to ensure random effects models would be reasonable for explaining sales measured in dollars per capita, grams per user, or market share; its panel data linear regression feature was then used to analyse those models with price as the random effects variable. Next, SPSS's General Linear Model 
feature was used to analyse regression models that included province as a fixed effect (via dummy variables) instead of price as a random effect.

\section{Results}

\section{National outcomes}

Canada's legal recreational sales began at $\$ 45.4$ million in October 2018 and increased to $\$ 124.7$ million by September 2019. In per capita terms, monthly sales rose from $\$ 1.22$ in October to $\$ 3.34$ in September, totalling $\$ 25.92$ for the year. The monthly grams sold per user grew from 1.19 to 3.51 , for an annual total of 26.21 grams.

Figure 2 illustrates the corresponding growth in recreational products' share of overall cannabis consumption volume. The centre line shows market shares relative to the consumption estimate's midpoint, while the outer dotted lines are relative to the prediction interval's lower and upper limits, all adjusted for month length. Sales began in October with a 7.8\% market share, hovered around $11 \%$ for five months, and then grew steadily to reach $23.7 \%$ in September (interval: $19.4 \%$ to $29.4 \%$ ). Over the same period, monthly legal medical sales (not shown) varied between $6.8 \%$ and $9.5 \%$ of overall consumption. For recreational and medical products combined, the total share in September was $31.7 \%$ (interval: $26.0 \%$ to $39.4 \%$ ).

For the year overall, market shares averaged $14.5 \%$ (interval: $11.9 \%$ to $18.1 \%$ ) for recreational products, $8.4 \%$ (interval: $6.9 \%$ to $10.5 \%$ ) for medical ones. and $23.0 \%$ (interval: $18.9 \%$ to $28.5 \%$ ) for both combined. With respect to product categories, legal products represented $35 \%$ of the smaller processed segment but just $18 \%$ of the larger dry segment.

Table 2 shows the Pearson correlations $r$ and their significance $p$ for four variables, using $N=12$ months of national data: recreational market share, store density, dry finished goods production, and oil finished goods production. (The table omits dollars per capita and grams per user because at the national level they were perfectly correlated with market share.) Market share had strong positive correlations with store density and dry production, which were themselves positively correlated. By contrast, oil production had no statistically significant correlations.

The plot in Figure 3 further explores the relationship between market share and store density by illustrating how both increased over time. It however shows a small zig-ag during the November-to-March period, when store densities continued increasing while market shares stagnated. This implies the stagnation was not due to a lack of stores.

The stagnation was instead apparently due to limited dry product supplies. Figure 4 plots monthly recreational dry sales volume alongside the "available" dry finished goods production: i.e., the amount of production available to recreational distributors after subtracting medical sales, exports, and product disposals. It shows that until February, dry production barely supported existing sales and was insufficient to fuel much growth. It was only in March that production grew substantially, thereby enabling sales and market shares to begin growing in April, as previously displayed in Figures 1, 2, and 3. 
By contrast, Figure 5 shows that available production of oil was several times greater than recreational sales. This explains why oil production levels were uncorrelated with sales. In fact, production dropped in the last three months because producers and distributors had by then accumulated excessively large inventories.

To quantify the above-mentioned relationships, a structural equation model was used to test whether dry and oil finished production might have influenced store density, and whether all three variables might have influenced recreational market share. Figure 6 displays the model's structure, along with the resulting standardised regression coefficient $\beta$ and significance $p$ for each potential relationship, and the resulting fit $R^{2}$ for each dependent variable. A chi-squared test showed no reason to reject the model $(p=.799)$, while both the normed fit index (NFI $=$ $.992)$ and goodness of fit index $(\mathrm{GFI}=.997)$ indicated the model suited the limited data.

The modelling confirmed what Figures 2 to 5 had indicated: dry production had a strong positive influence on store density, which in turn strongly influenced market share; dry production also had a weaker direct influence on market share. By contrast, oil production showed no significant influence on either store density or market share. The model explained unusually large portions of the monthly variation in store density and market share despite having only three explanatory variables. This was because potential demand-side factors such as consumer tastes, marketing efforts, and weather had little chance to affect sales so long as dry products were in short supply and sold out quickly.

It appears the dry shortage was aggravated by producers' losses of finished products (McRuer, 2020). From November to September, the sum of producers' reported dry inventories, recreational shipments, medical sales, and exports equated to 17,524 kg less finished goods than their reported production implied. It seems unlikely this was merely an accounting error, as it represented $13 \%$ of finished dry output; and across the 11 months, there were 10 negative discrepancies and only 1 positive one. Consequently, the difference was more likely due to losses of finished products, whether due to routine inventory "shrinkage" or to large scale scrapping because of quality problems (Doucette, 2020).

With oil products, by comparison, there were 3,441 litres more finished goods in inventories than the reported production should have enabled. Since that deviation was positive and just $2 \%$ of total output, it seems likely due to reporting errors.

\section{Provincial outcomes}

This subsection compares sales across the 10 provinces. Since preparing the provincial data involved more assumptions and approximations, readers should pay less attention to the specific numerical values and focus instead on the relative comparisons among them.

While province-level sales tended to follow the same general pattern as the national total, there was still much variety across the 10 provinces. To illustrate this, Figure 7 plots each province's monthly sales in grams per user. Sales seemed relatively stationary in two provinces but showed substantial upward trends in the other eight. Table 3 summarizes each province's results for September 2019, showing dollars per capita, grams per user, and market share. 
Ontario had the lowest values and Prince Edward Island had the highest: e.g., their market shares were $13 \%$ and $70 \%$, respectively. The latter province was somewhat of an exception, as the nextbest provincial values were all much lower: e.g., Quebec's 54\% share was the second highest.

Table 4 shows the correlations between the three sales measures and store density, using $N=120$ province-month values. The three sales measures were strongly correlated, suggesting that the translation from dollars to grams to shares did not distort the measures' statistical properties. Store density also was positively correlated with all three sales measures.

To quantify the interprovincial differences, the sales measures were analysed using panel data linear regression. Random effects models were considered first, with provincial average retail pricing as the random effect, and provincial monthly store density, national monthly dry cannabis production, and national monthly cannabis oil production as the other explanatory variables. The regression output (not shown) reported good results for dollars per capita $\left(R^{2}=\right.$ $43.5 \%)$, grams per user $\left(R^{2}=44.4 \%\right)$, and market share $\left(R^{2}=43.8 \%\right)$. However, the residual plots showed systematic differences remained between provinces in all three cases.

Consequently, fixed effects models were considered next. In these, province was included as a categorical factor using dummy variables, while provincial pricing was omitted. (Because only one annual price measure was calculated per province, province and price could not meaningfully be included together.) Using province rather than price as an explanatory variable provided much better model fits: for each one, the $R^{2}$ roughly doubled and the residual plots showed no obvious systematic gaps. This indicates that although pricing was an important difference between provinces, it was not the only one. Table 5 summarizes the three regression models' results, showing each variable's significance $p$ and partial $\eta^{2}$ measure of effect size, plus the overall model fit $R^{2}$. As with the national analysis, all the variables were significant except oil production. While province (and the many details it subsumed) showed the biggest influence, store density and dry production also mattered; stores were more influential for sales dollars, while production was more influential for market shares.

The regressions also yielded marginal means for each provincial dummy variable (not shown). In some sense those represented the "quality" of each province's retail system (including pricing, operating hours, product selection, etc.), whereas store density measured its "quantity". The 95\% Bonferroni confidence intervals classified the means into several tiers, such that interprovincial differences were significant between tiers but not within them. For all three sales measures, Prince Edward Island was alone in the top tier, while the other tiers' membership varied slightly with the sales measure.

- For dollars per capita: Nova Scotia was alone in the second tier, while the other eight provinces blurred together in the third tier.

- For grams per user: Nova Scotia, Quebec, New Brunswick, and Manitoba made up the second tier, leaving the other five provinces in the third one.

- For market share: Quebec was alone in the second tier; Nova Scotia, New Brunswick, and Manitoba composed a new third tier; and the other provinces were in the fourth. 
Quebec's second-place market share partly reflected the below-average intensity of use that MPG (2018) had built into its consumption estimate for that province. Nova Scotia's second-place dollars per capita might indicate it charged higher-than-average prices; recall that its mark-ups were unknown. Also note that as the analysis moved from dollars to grams to shares, it detected more differences among the provinces, without radically altering any of the groupings; this implies the extra approximations required for the latter measures were both worthwhile and reasonable.

\section{Discussion}

\section{Findings and implications}

This study estimated that by the 12th month of legalisation, recreational and medical cannabis sales together covered roughly one-third of Canada's consumption. On the one hand, that represented substantial progress toward the federal government's goals of expelling untested products and criminal suppliers from the market; on the other hand, it meant those products and suppliers still retained two-thirds of that market.

The analysis indicated that legal products captured market share largely to the extent they were available from producers, accessible in stores, and priced low. For the country overall, sales were held back by shortages of dry products and licensed stores. The dry shortage directly impacted sales by making fewer products available, and indirectly by causing provinces to delay retail expansion. These results support complaints that product shortages initially were widespread and refute federal government claims of "adequate" supplies (Blair, 2019a). However, they also indicate that after those shortages were resolved, the responsibility for sales growth shifted to the provincial governments, as they regulated the quality and quantity of their retailing systems. This supports suggestions that sales changed from being producer-constrained to retailer-constrained as the year progressed (Armstrong, 2019).

The analysis also revealed large differences across the 10 provinces. Some, like Alberta, apparently did well by having many stores relative to their populations. Others, like Quebec, did well because low prices and other factors apparently compensated for their store scarcity.

The results suggest that provinces with low legal market shares can increase them by adding stores, and this has already started. Canada's store total is more than 1,100 at the time of this writing and will likely exceed 2,000 after Ontario processes its retail license application backlog (Armstrong, 2020). Of course, while more stores will attract more existing users, they might also attract more new ones, as apparently happened in Washington (Everson et al., 2019).

Lowering prices is another way to boost legal market shares, and this has also begun. Quebec began selling "value-priced" dry products under \$5 per gram including taxes in October 2019, and several other provinces later followed suit (Israel, 2020).

On the one hand, Canada's results provide further evidence that it takes time to establish a new legal cannabis industry. In Washington state, for example, prices were still dropping, and sales volumes were still rising, two years after legalisation (Davenport, in press; Smart et al., 
2017). On the other hand, Prince Edward Island's results demonstrate that legal cannabis can dominate illegal products when the ingredients are right. That province opened ample stores for its small market, offered relatively low prices, and avoided most of the dry product shortages (Prince Edward Island Cannabis Management Corporation 2019: 19). Thus, by September 2019, legal recreational products represented $70 \%$ of the province's consumption.

\section{Limitations and future research}

One limitation of this study was the lack of detailed provincial data. Provincial cannabis agencies have the most information about recreational sales, especially where they operate all the stores; but despite public ownership, public mandates, and public attention, most provide minimal public disclosure. Consequently, this study indirectly estimated provincial results using federal data. More disclosure from provincial agencies would greatly help future research. Washington state, for instance, reports monthly sales at the retailer license level, allowing for very detailed analysis (Davenport, in press; Hollenbeck \& Uetake, 2020; Smart et al., 2017).

Such future research could examine later stages of Canada's legalisation. For example, in year two of recreational sales, two new product categories appeared: low-priced "value" dry cannabis that undercuts illegal product prices (Israel, 2020); and high-priced cannabis drinks unlike anything illegal sellers offer (Charlebois et al., 2020). These represent two very different strategies for competing against illicit products. How successful will each one be?

Future research could also more precisely estimate Canada's cannabis consumption and the extent to which that changed after legalisation day. How much did consumption grow after legalisation? How much of that growth simply represented ongoing trends, how much was due to legalisation itself, and how much was due to legal stores opening? How has consumption changed in terms of product formats (e.g., vaping versus smoking), potencies (e.g., THC versus CBD), or pricing (e.g., discount versus premium brands)? Those are important questions but require very different data and methodology than are used herein. 


\section{References}

Anderson, P.L. (2020) Blue smoke and seers: measuring latent demand for cannabis products in a partially criminalized market, Business Economics 55 \#1: 26-40. https://doi.org/10.1057/s11369-019-00159-y

Armstrong M.J. (2020) Ontario's cannabis agency earns \$18.6 million, beating Alberta's but lagging Québec's. The Conversation, 20 Oct. https://theconversation.com/ontarios-cannabisagency-earns-18-6-million-beating-albertas-but-lagging-quebecs-148151

Armstrong M.J. (2019) Why Canada's legal marijuana market needs more stores to thrive. Globe and Mail, Sep 5. Accessed 24 Jun 2020.

https://www.theglobeandmail.com/robcannabispro/article-why-canadas-legal-marijuanamarket-needs-more-stores-to-thrive/

Armstrong M.J., Malleck D., (2019) Don't foredoom cannabis legalisation to failure, Canadian Medical Association Journal 191 \#3, E84. https://doi.org/10.1503/cmaj.71136

Blair B. (2019a) @BBlair Twitter comment, 13:25 on 16 Jan. Accessed 24 Jun 2020. https://twitter.com/BillBlair/status/1085649196558872577

Blair B. (2019b) @ BBlair Twitter comment, 08:09 on 30 Jan. Accessed 24 Jun 2020. https://twitter.com/billblair/status/1090643226254561285?lang=en

Canadian Centre on Substance Use and Addiction (2019) Clearing the Smoke on Cannabis Highlights - An Update. https:/www.ccsa.ca/sites/default/files/2019-10/CCSA-ClearingSmoke-on-Cannabis-Highlights-2019-en.pdf

Cannabis Act (2018). S.C. 2018, c. 16. https://laws-lois.justice.gc.ca/eng/acts/c-24.5/

Charlebois S., Music J., Sterling B., Somogy S. (2020) Edibles and Canadian consumers' willingness to consider recreational cannabis in food or beverage products: A second assessment. Trends in Food Science \& Technology 98 April, 25-29. https://doi.org/10.1016/j.tifs.2019.12.025

Childs J., Stevens J. (2019) The state must compete: Optimal pricing of legal cannabis. Canadian Public Administration 62 \#4, 656-673. https://doi.org/10.1111/capa.12352

Davenport S. (in press) Price and product variation in Washington's recreational cannabis market. International Journal of Drug Policy, Online 12 Sep 2019, 102547. https://doi.org/10.1016/j.drugpo.2019.08.004

Doucette T. (2020) Quality control at scale still a challenge for Canadian cannabis industry, says prof. CBC News, 7 Jan. Accessed 12 Jul 2020.

https://www.cbc.ca/news/canada/windsor/cannabis-quality-control-niagara-college-1.5417336

Everson E.M., Dilley J.A., Maher J.E, Mack C.E. (2019) Post-Legalization Opening of Retail Cannabis Stores and Adult Cannabis Use in Washington State, 2009-2016. American Journal of Public Health 109 \# 9: 1294-1301. https://doi.org/10.2105/AJPH.2019.305191

French J. (2018). AGLC hits pause on retail cannabis licences as nation sees pot shortage, Edmonton Journal, 22 Nov. Accessed 8 Jul 2020. https://edmontonjournal.com/cannabis/cannabis-business/aglc-hits-pause-on-retail-cannabislicences-as-nation-sees-pot-shortage

Hammond D. (in press) Communicating THC levels and 'dose' to consumers. International Journal of Drug Policy, https://doi.org/10.1016/j.drugpo.2019.07.004

Hart C.L. (in press) Exaggerating Harmful Drug Effects on the Brain Is Killing Black People, Neuron. https://doi.org/10.1016/j.neuron.2020.06.019 
Health Canada, 2017. Canadian cannabis survey 2017 - Summary. December 19. https://www.canada.ca/en/health-canada/services/publications/drugs-healthproducts/canadian-cannabis-survey-2017-summary.html

Health Canada (2020) Cannabis market data: Overview. 24 Feb. Accessed 8 Jul 2020. https://www.canada.ca/en/health-canada/services/drugs-medication/cannabis/researchdata/market.html?hootPostID=82e043504cdc02fd5d414a18ef15a658

Hollenbeck B., Uetake K. (2020) Taxation and Market Power in the Legal Marijuana Industry, SSRN 3237729, 25 Apr. Accessed 8 Jul 2020. https://ssrn.com/abstract=3237729

Hunt P., Pacula R.L. (2017) Early Impacts of Marijuana Legalisation: An Evaluation of Prices in Colorado and Washington, Journal of Primary Prevention 38: 221-248. https://doi.org/10.1007/s10935-017-0471-x

Israel S. (2020) Canada's discount cannabis segment heats up with competing value brands. Marijuana Business Daily, 24 Jun. Accessed 8 Jul 2020. https://mjbizdaily.com/canadasdiscount-cannabis-segment-heats-up-with-competing-value-brands/

Lancionea S., Wadea K., Windle S.B., Filion K.B., Thombs B.D., Eisenberg M.J. (2020) Nonmedical cannabis in North America: an overview of regulatory approaches. Public Health 178 January, 7-14. https://doi.org/10.1016/j.puhe.2019.08.018

Levasseur J. (2019) More legal cannabis needed to break black market: province. CBC News, 27 Mar. Accessed 24 Jun 2020. https://www.cbc.ca/news/canada/manitoba/cannabis-supplyblack-market-1.5074428

Mahamad S., Wadsworth E.,Rynard V., Goodman S., Hammond D. (2020) Availability, retail price and potency of legal and illegal cannabis in Canada after recreational cannabis legalisation. Drug and Alcohol Review 39 \#4, 337-346. https://doi.org/10.1111/dar.13069

Manitoba Liquor \& Lotteries (2019) Annual Report 2018/19. https://www.mbll.ca/sites/mbll_corporate_2/files/pamphlets/pdf/ar_mbll_final_2018-2019.pdf

McRuer G. (2020). Canadian LPs Destroyed or Lost \$2.1 Billion of Weed Since Legalization, Blunt Economics, 8 Jan. Accessed 12 Jul 2020. http://www.blunteconomics.com/canadianlps-destroyed-or-lost-2-1-billion-of-weed-since-legalization/

MPG (2018). Cannabis Demand in Canada, draft version 18. Report commissioned by Health Canada from Marijuana Policy Group and BOTEC Analysis.

Obradovic I. (in press) From prohibition to regulation: A comparative analysis of the emergence and related outcomes of new legal cannabis policy models (Colorado, Washington State and Uruguay). International Journal of Drug Policy. https://doi.org/10.1016/j.drugpo.2019.11.002

Office of the Parliamentary Budget Officer (2016). Legalized Cannabis: Fiscal Considerations. 1 Nov, Ottawa. Accessed 26 Aug 2020. http://www.pbo-dpb.gc.ca/web/default/files/ Documents/Reports/2016/Legalized\%20 Cannabis/Legalized\%20Canabis\%20Fiscal\%20 Considerations_EN.pdf.

Ontario Ministry of Finance (2018). Ontario Takes a Phased Approach to Cannabis Retail Licensing Due to National Supply Shortages, 13 Dec. Accessed 10 Jul 2020. https://news.ontario.ca/mof/en/2018/12/ontario-takes-a-phased-approach-to-cannabis-retaillicensing-due-to-national-supply-shortages.html

Owermohle S. (2019) 'No one is going to hire you': Vets face obstacles to using medical marijuana. Politico, 23 May. Accessed 20 Jun 2020. https://www.politico.com/story/2019/05/23/vets-medical-marijuana-1470413

Prince Edward Island Cannabis Management Corporation (2019). 2019 Annual Report. https://peicannabiscorp.com/pages/corporate 
Rotermann M. (2020) What has changed since cannabis was legalized? Health Reports 31 \#2: 11-20. 19 Feb. https://www.doi.org/10.25318/82-003-x202000200002-eng

Sen A., Wyonch R. (2018) Cannabis Countdown: Estimating the Size of Illegal Markets and Lost Tax Revenue Post-Legalisation. Commentary No. 523, C.D. Howe Institute, Toronto. https://www.cdhowe.org/public-policy-research/cannabis-countdown-estimating-size-illegalmarkets-and-lost-tax-revenue-post-legalisation

Smart R., Caulkins J.P, Kilmer B., Davenport S., \& Midgette G. (2017) Variation in cannabis potency and prices in a newly legal market: evidence from 30 million cannabis sales in Washington state. Addiction 112, 2167-2177. https://doi.org/10.1111/add.13886

Société québécoise du cannabis (2019) Rapport Annuel 2019. https://www.sqdc.ca/fr-CA/apropos/acces-a-l-information/Publications

Statistics Canada (2019a) National Cannabis Survey: Detailed information for fourth quarter 2019. 12 Dec. Accessed 8 Jul 2020.

https://www23.statcan.gc.ca/imdb/p2SV.pl?Function=getSurvey\&SDDS=5262

Statistics Canada, (2019b) The Retail Cannabis Market in Canada: A Portrait of the First Year. Analysis in Brief 11-621-M, 12 Dec. https://www150.statcan.gc.ca/n1/pub/11-621-m/11-621m2019005-eng.htm

Statistics Canada, (2019c). StatsCannabis data availability: Crowdsourced cannabis prices, third quarter 2019. 9 Oct. Accessed 27 Aug 2020. https://www150.statcan.gc.ca/n1/dailyquotidien/191009/dq191009a-eng.htm

Statistics Canada (2020) Retail trade sales by province and territory. 12 May. Accessed 8 Jul 2020. https://www150.statcan.gc.ca/t1/tbl1/en/cv.action?pid=2010000801 


\section{Table 1.}

The first three columns show each province's extra ad valorum excise tax (if any), its estimated combined retail-wholesale price mark-up, and its combined federal-provincial sales tax rate. The last two columns show the store density (in stores per million users), first averaged across all 12 months and then just for September 2019.

\begin{tabular}{lccccc}
\hline & $\begin{array}{c}\text { Extra } \\
\text { excise } \\
\text { tax }\end{array}$ & $\begin{array}{c}\text { Retail- } \\
\text { wholesale } \\
\text { mark-up }\end{array}$ & $\begin{array}{c}\text { Retail } \\
\text { sales } \\
\text { taxes }\end{array}$ & $\begin{array}{c}\text { Store } \\
\text { density } \\
\text { Average }\end{array}$ & $\begin{array}{c}\text { Store } \\
\text { density } \\
\text { September }\end{array}$ \\
\hline Newfoundland & - & $83 \%$ & $15 \%$ & 266 & 271 \\
Prince Edward Island & - & $35 \%$ & $15 \%$ & 152 & 166 \\
Nova Scotia & - & $54 \%$ & $15 \%$ & 58 & 58 \\
New Brunswick & - & $55 \%$ & $15 \%$ & 158 & 158 \\
Quebec & - & $23 \%$ & $14.975 \%$ & 17 & 21 \\
Ontario & $3.9 \%$ & $80 \%$ & $13 \%$ & 4.6 & 12 \\
Manitoba & - & $66 \%$ & $11 \%$ & 114 & 144 \\
Saskatchewan & $6.45 \%$ & $52 \%$ & $11 \%$ & 158 & 255 \\
Alberta & $16.8 \%$ & $52 \%$ & $5 \%$ & 162 & 411 \\
British Columbia & - & $39 \%$ & $12 \%$ & 29 & 85 \\
\hline
\end{tabular}

\section{Table 2.}

Pearson correlation coefficients $r$ (top number) and their significance $p$ (bottom number) for $N=$ 12 months of country-level measurements.

\begin{tabular}{lccc}
\hline & $\begin{array}{c}\text { Recreational } \\
\text { share }\end{array}$ & $\begin{array}{c}\text { Store } \\
\text { density }\end{array}$ & $\begin{array}{c}\text { Dry } \\
\text { production }\end{array}$ \\
\hline Store density & .980 & & \\
Dry production & .000 & & \\
& .808 & .740 & \\
Oil production & .001 & .006 & \\
& -.039 & -.132 & .077 \\
& .904 & .682 & .813 \\
\hline
\end{tabular}




\section{Table 3.}

Provinces' legal recreational cannabis sales during September 2019, estimated in dollars per capita, grams per user, and share of total consumption volume.

\begin{tabular}{lccc}
\hline & $\begin{array}{c}\text { Dollars } \\
\text { per capita }\end{array}$ & $\begin{array}{c}\text { Grams } \\
\text { per user }\end{array}$ & $\begin{array}{c}\text { Market } \\
\text { share }\end{array}$ \\
\hline Newfoundland & $\$ 6.24$ & 4.5 & $30 \%$ \\
Prince Edward Island & $\$ 9.45$ & 10.5 & $70 \%$ \\
Nova Scotia & $\$ 6.04$ & 4.0 & $27 \%$ \\
New Brunswick & $\$ 3.73$ & 4.1 & $28 \%$ \\
Quebec & $\$ 2.84$ & 5.5 & $54 \%$ \\
Ontario & $\$ 2.31$ & 2.0 & $13 \%$ \\
Manitoba & $\$ 4.50$ & 5.2 & $31 \%$ \\
Saskatchewan & $\$ 6.35$ & 5.0 & $30 \%$ \\
Alberta & $\$ 6.23$ & 5.2 & $31 \%$ \\
British Columbia & $\$ 2.52$ & 2.7 & $16 \%$ \\
\hline Canada & $\$ 3.34$ & 3.51 & $23.7 \%$ \\
\hline
\end{tabular}

\section{Table 4.}

Pearson correlation coefficients $r$ (top number) and their significance $p$ (bottom number) for $N=$ 120 province-months of estimates for retail store density and for recreational sales in dollars per capita, grams per user, and share of consumption volume.

\begin{tabular}{lccc}
\hline & $\begin{array}{c}\text { Store } \\
\text { density }\end{array}$ & $\begin{array}{c}\text { Dollars } \\
\text { per capita }\end{array}$ & $\begin{array}{c}\text { Grams } \\
\text { per user }\end{array}$ \\
\hline Dollars per capita & .613 & & \\
Grams per user & .000 & & \\
& .465 & .872 & \\
Market share & .000 & .000 & \\
& .358 & .783 & .970 \\
& .082 & .000 & .000 \\
\hline
\end{tabular}




\section{Table 5.}

Linear regression results for three fixed effects panel models for provincial monthly sales, estimated respectively in dollars per capita, grams per user, and market share. The table shows each explanatory variable's significance $p$ and effect size partial $\eta^{2}$, as well as the overall model fit $R^{2}$. The provincial dummy variables are omitted for brevity.

\begin{tabular}{lcccccc}
\hline & Dollars & \multicolumn{3}{c}{ Grams } & \multicolumn{3}{c}{ Share } \\
& $p$ & $\eta^{2}$ & $p$ & $\eta^{2}$ & $p$ & $\eta^{2}$ \\
\hline Constant & .002 & $9 \%$ & .031 & $4 \%$ & .014 & $6 \%$ \\
Province & .000 & $86 \%$ & .000 & $88 \%$ & .000 & $88 \%$ \\
Store density & .000 & $33 \%$ & .000 & $24 \%$ & .000 & $16 \%$ \\
Dry production & .000 & $15 \%$ & .000 & $22 \%$ & .000 & $22 \%$ \\
Oil production & .911 & $0 \%$ & .835 & $0 \%$ & .912 & $0 \%$ \\
$R^{2}$ & & $91.4 \%$ & & $90.8 \%$ & & $90.1 \%$ \\
\hline
\end{tabular}

\section{Figure 1.}

Total cannabis retail sales volumes, in kilograms of dry and litres of oil, recreational and medical sales combined, for the 12 months before legalisation and the 12 months thereafter.

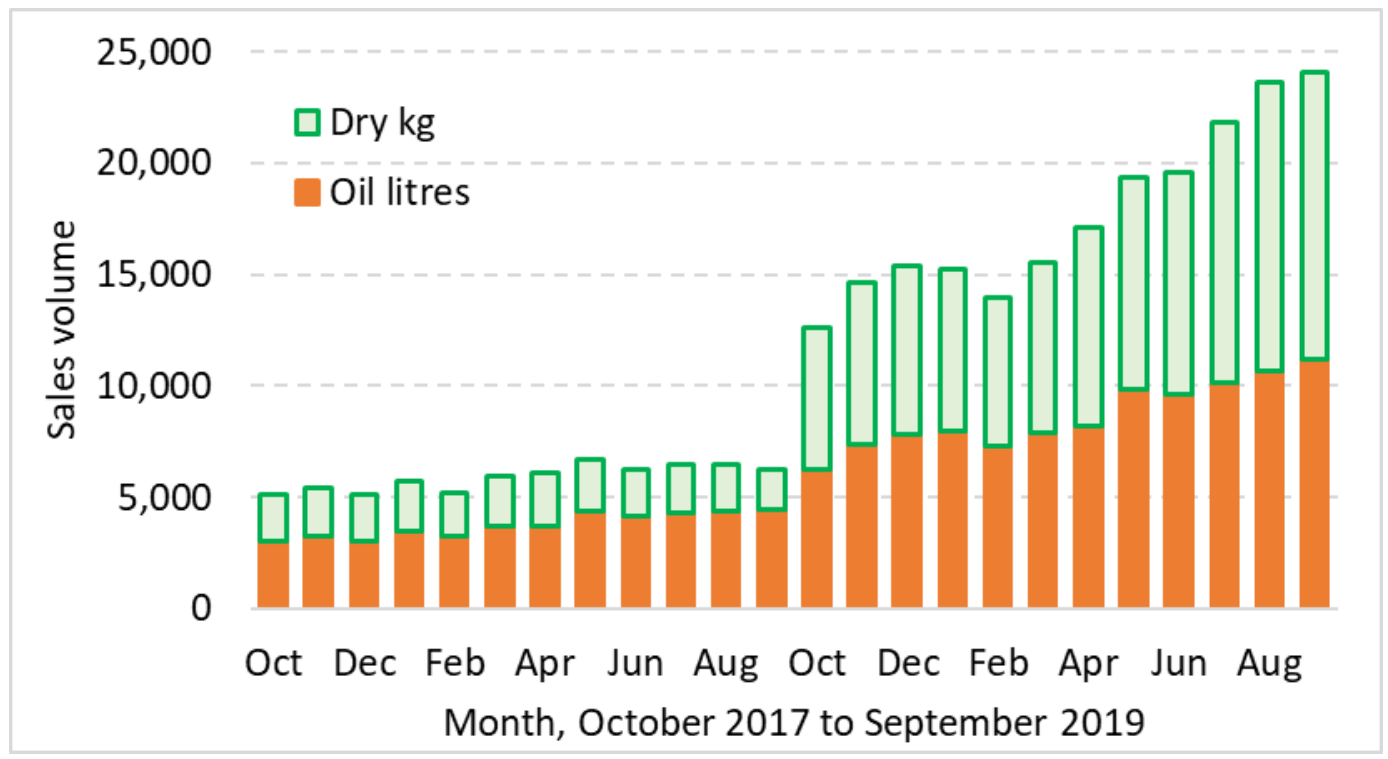




\section{Figure 2.}

Estimated Canadian legal recreational cannabis market shares, relative to the consumption estimate's midpoint (solid line with markers) and its upper and lower limits (dotted lines).

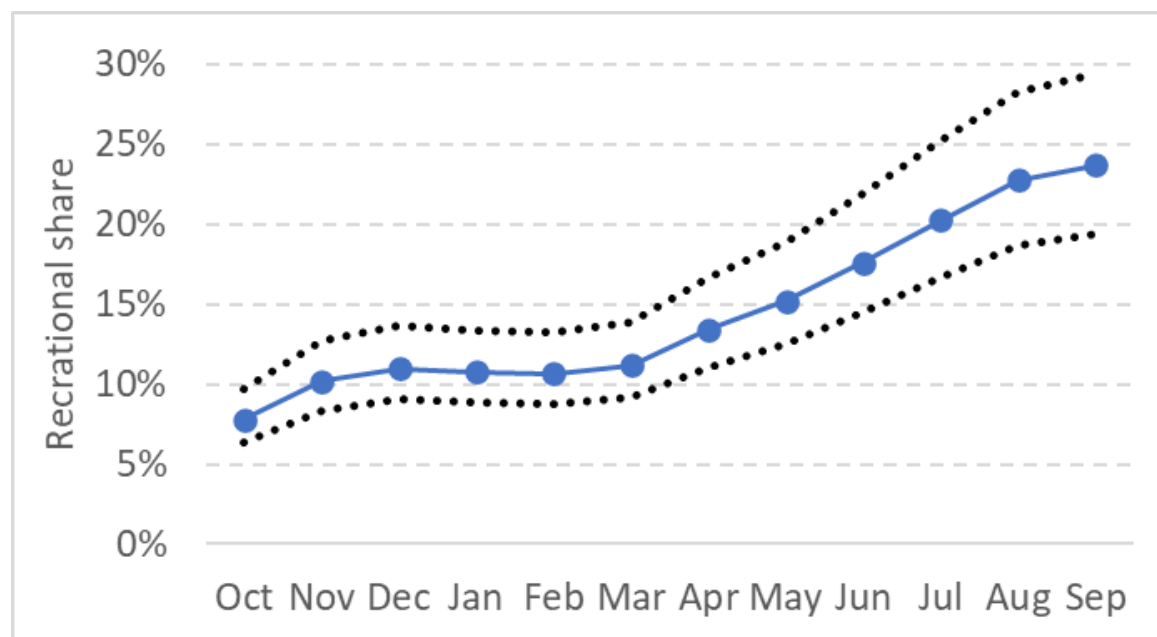

\section{Figure 3.}

Canadian recreational market share (\%) versus store density (stores per million users). Each dot represents one month's results, from October 2018 (lower left) to September 2019 (upper right).

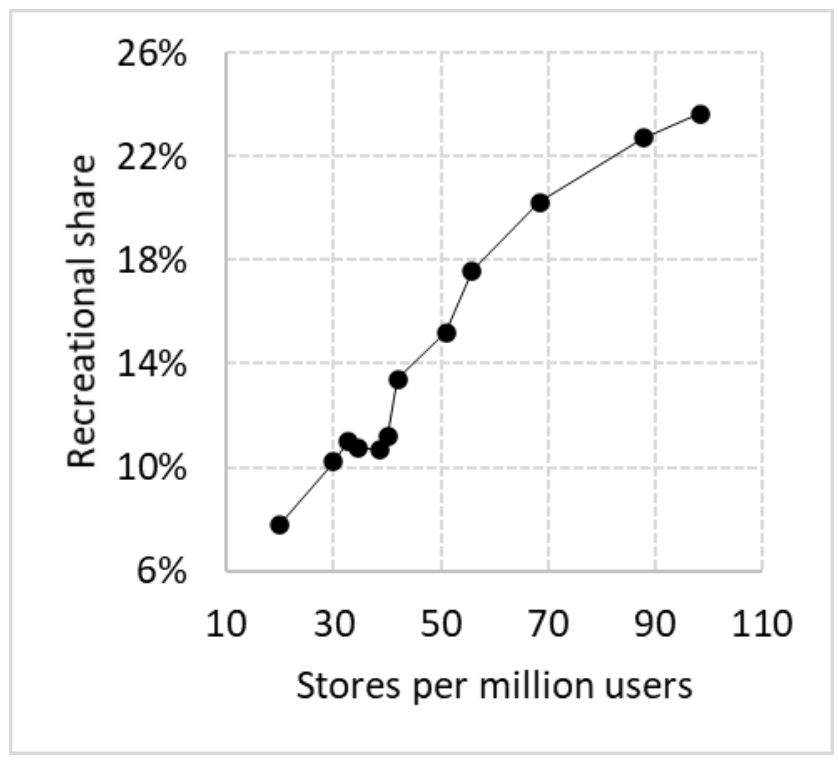




\section{Figure 4.}

Monthly dry cannabis recreational sales volume, as compared to finished goods production available after subtracting medical sales, disposals, and exports.

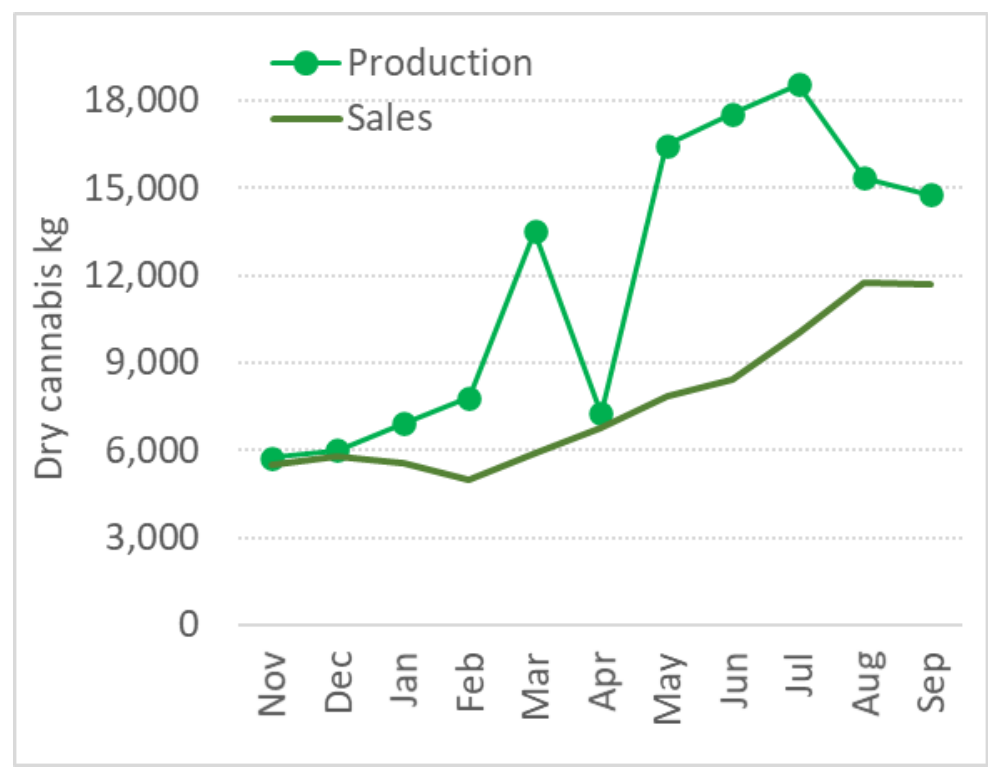

\section{Figure 5.}

Monthly cannabis oil recreational sales volume, as compared to finished goods production available after subtracting medical sales, disposals, and exports.

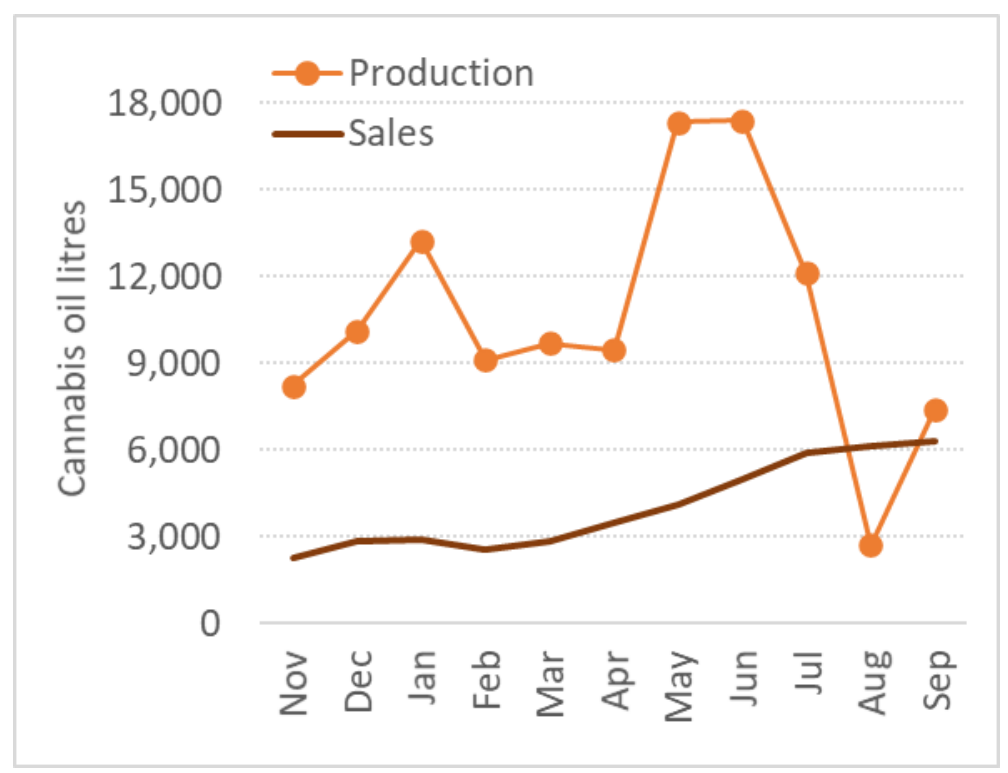




\section{Figure 6.}

Structural equation model for $N=12$ months of national data. Numbers on boxes indicate fit $R^{2}$; numbers on arrows indicate standardized regression coefficients $\beta$ and significance $p$; solid arrows are significant relationships, dashed ones are not.

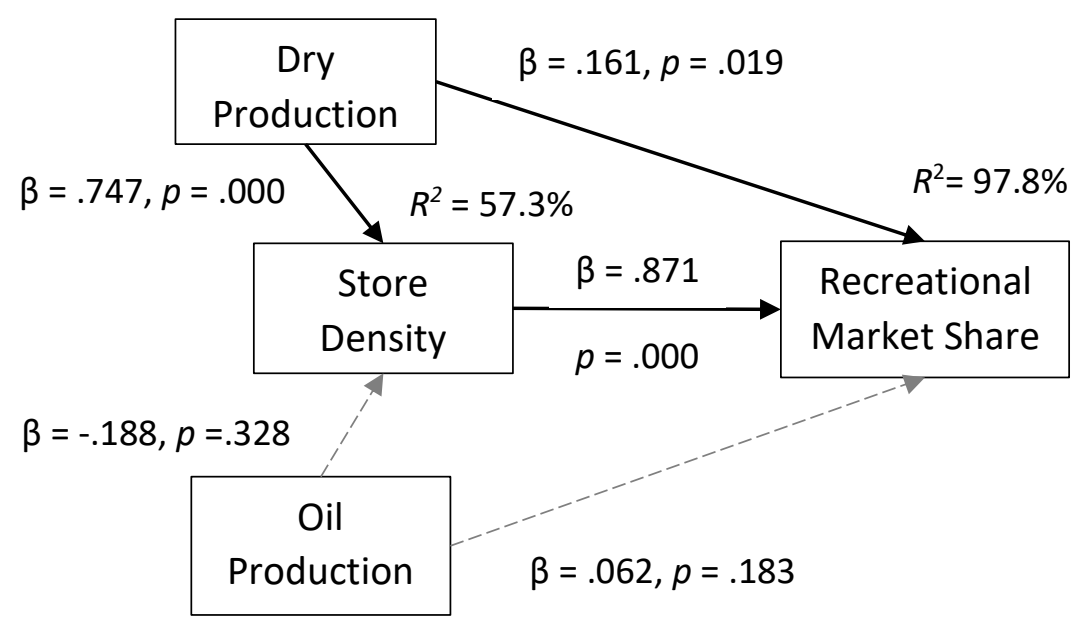

\section{Figure 7.}

Estimated recreational cannabis sales in grams per user for each province and month.

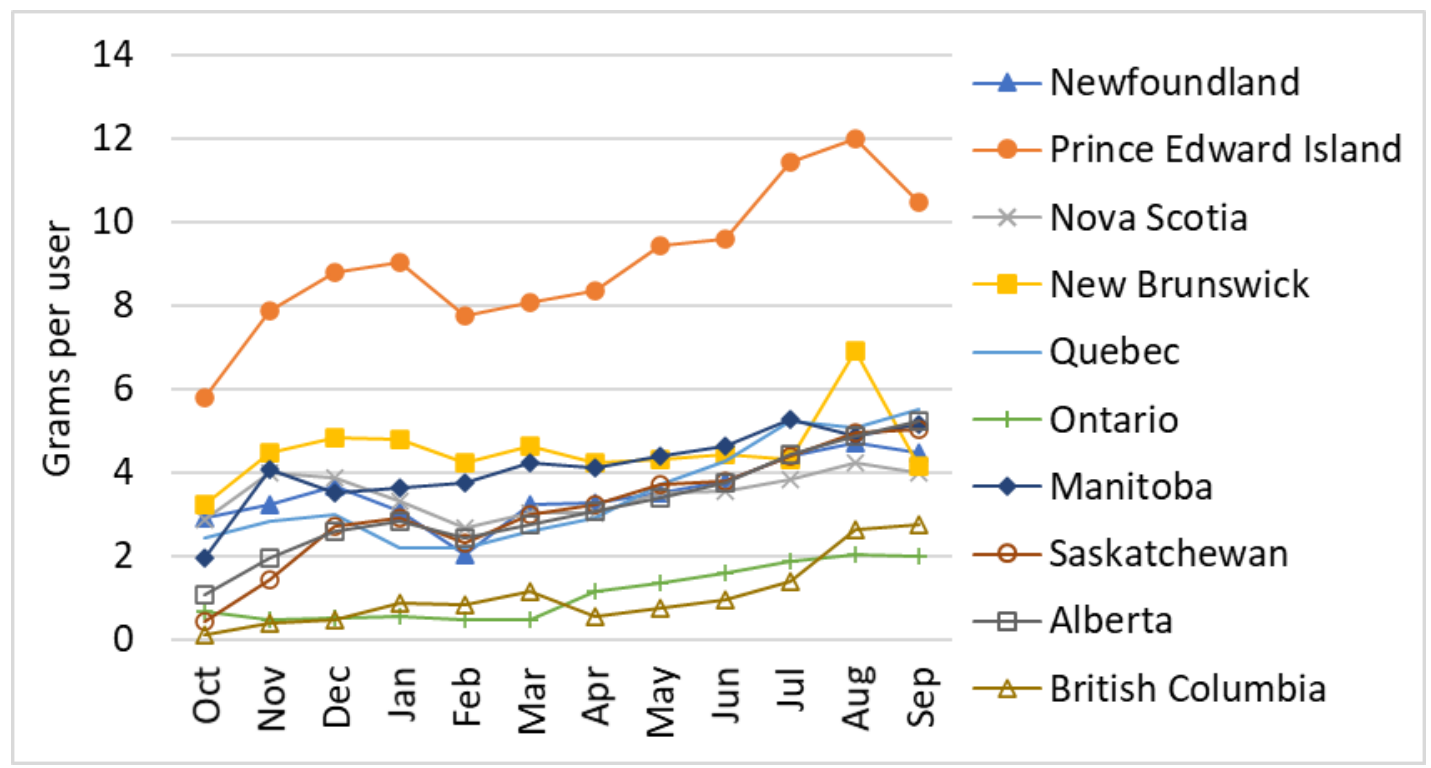

